\title{
Forming Trust in E-Mentoring: A Research Agenda
}

\author{
Joanne D. Leck ${ }^{1}$, Penny M. Wood ${ }^{2}$ \\ ${ }^{1}$ Telfer School of Management, University of Ottawa, Ottawa, Canada; ${ }^{2}$ Director General Military Personnel Research and Analysis, \\ Department of National Defence, Ottawa, Canada. \\ Email: leck@telfer.uottawa.ca, penny.wood@forces.gc.ca
}

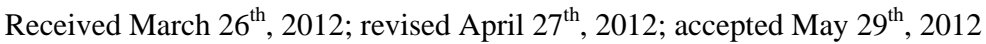

\begin{abstract}
Mentoring has been identified as a valuable tool for learning and career development, as well as organizational advancement. E-mentoring has increased in popularity as a means of creating global access to mentors while reducing organizational training costs, and reducing both time and geographical constraints for mentors and mentees. E-mentoring has proven to most benefit the mentee and mentor when mutual trust has been established. However, e-mentoring is still a relatively new phenomenon and it is unclear how online trust is established and sustained between mentors and mentees. This paper presents a research agenda to better understand how trust is formed in e-mentoring.
\end{abstract}

Keywords: Mentoring; E-Mentoring; Trust; Online Trust; Interpersonal Trust

\section{Introduction}

Mentoring is the interaction between a more experienced senior person called a mentor, with a less experience junior person called a mentee, for emotional and career support [1-9]. "Traditionally, mentoring has been defined as an intense, dyadic relationship in which a more senior, experienced person, called a mentor, provides support and assistance to a more junior, less experienced colleague, referred to as a protégé or mentee. Although mutually beneficial, mentoring in the workplace typically is focused on enhancing the professional development of the mentee" [10].

Mentoring has been indentified to be one of the most valuable practices to help employees navigate the workplace and advance their careers in business, industry and education [11]. Over the last 25 years organizations have realized the benefits of mentoring and launched mentoring programs into their developmental training plans [11].

A mentoring relationship has the ability to propel career and psychosocial development for both mentors and mentees [7]. Psychosocial development refers to an individual's interaction within a particular social environment, while career development refers to an individual's enhancement in learning within an organization [7]. Kram describes career functions as "those aspects of the mentoring relationship that enhance learning the ropes and preparing for advancement in an organization” and psychosocial functions as "those aspects of a mentoring relationship that enhance a sense of competence, clarity of identity, and effectiveness in a professional role" [7].
The career functions include coaching, protecting, sponsoring, increasing exposure, assigning challenging projects and increasing visibility [7]. The psychosocial functions involve other aspects such as role modeling, counseling, friendship, acceptance and confirmation [7].

\section{Benefits to Mentoring}

Mentees can advance their careers as they learn from their mentors and are provided personal support, feed-back, encouragement, friendship, advice and guidance from their mentors [12]. Mentees also learn new skills, modify behaviors and work more independently on the advice and guidance provided by mentors. Many mentees report a gain in self esteem [12], increased confidence in managing their career roles [12] and mentoring augments career outcomes [13]. Mentees experience greater work satisfaction, career mobility, career and organizational commitment, recognition and lower turnover, as compared to those who have not been in a mentoring relationship [1, 4]. Furthermore, mentees also acquire greater career benefits such as higher salaries, more promotions and better work performance appraisals, as compared to non-mentored individuals $[1,3,4,13]$ in addition to increased networking and visibility [13]. Lastly, mentoring assists mentees with the development of self-esteem and work identity [13].

\section{Benefits of Mentoring}

An organization that sustains intra-organizational mentoring also receives advantages from mentoring rela- 
tionships. Mentoring provides organizations several bene fits which include: increased productivity; increased recruiting ability; increased employee commitment to the organization; cost savings (as compared to other formal training programs); improved organizational communication; and enhancement of strategic planning ability [12]. In addition, mentoring can help in learning about the organization, augmenting the organizational culture [14] and providing entry into social networks that would otherwise be unavailable [13]. Mentoring can also contribute in creating a positive organizational environment by enhancing a clearer understanding of career commitments and expectations which result in enhancing employee performance, accelerating training opportunities and producing better trained employees [12,13]. Organizations also benefit from mentoring relationships as employees communicate more effectively as a result of their improved sense of loyalty and subsequently turnover rates are reduced [12]. Mentoring also has been identified as a highly useful tool for attracting new workers [12] and in retaining talent [15].

A brief summary of the benefits of mentoring is provided in Table 1.

\subsection{Limitations to Traditional Mentoring}

Despite the benefits to mentoring, traditional mentoring has important limitations. Traditional mentoring is normally contained within an organization or profession because it is dependent on both the mentor and mentee

Table 1. Benefits of mentoring [2,3,12,13,15,16,18].

\begin{tabular}{|c|c|c|}
\hline Organization & Mentor & Mentee \\
\hline $\begin{array}{l}\text { - Development of } \\
\text { employees } \\
\text { - Increased } \\
\text { commitment to the } \\
\text { organization } \\
\text { - Increase of } \\
\text { organizational culture } \\
\text { - Cost effectiveness } \\
\text { - Improved } \\
\text { organizational } \\
\text { communication } \\
\text { - Improved } \\
\text { organizational culture } \\
\text { - Distributes/retains } \\
\text { corporate knowledge } \\
\text { - Reduces turnover and } \\
\text { attrition } \\
\text { - Increased work } \\
\text { performance of } \\
\text { employees } \\
\text { - Increased recruiting } \\
\text { ability } \\
\text { - Enhancement of } \\
\text { strategic planning } \\
\text { - Accelerates training } \\
\text { - Increased employee } \\
\text { loyalty }\end{array}$ & $\begin{array}{l}\text { - Personal fulfillment } \\
\text { - Assistance on projects } \\
\text { - Financial rewards } \\
\text { - Increased confidence } \\
\text { - Increased self esteem } \\
\text { - Revitalized interest in } \\
\text { work } \\
\text { - Fosters positive } \\
\text { visibility } \\
\text { - Career advancement } \\
\text { - Increased leadership } \\
\text { skills } \\
\text { - Increased coaching } \\
\text { skills } \\
\text { - Increased recognition }\end{array}$ & $\begin{array}{l}\text { - Career advancement } \\
\text { - Personal support } \\
\text { - Learning and } \\
\text { development } \\
\text { - Increased confidence } \\
\text { - Increased self esteem } \\
\text { - Assistance and } \\
\text { feedback } \\
\text { - Fosters positive } \\
\text { visibility } \\
\text { - Career advancement } \\
\text { - Increased networking } \\
\end{array}$ \\
\hline
\end{tabular}

being in the same physical space. As such, mentees have a narrow selection of mentors to choose from given they are usually only available from within the organization. Even if a suitable mentor can be found within the organization, establishing and maintaining a mentoring relationship can be challenging as it requires both individuals to be in the same place at the same time for the communication exchange. Similarly, if either party changes jobs or relocates, the mentoring relationship is typically ended or erodes as the physical presence of both parties is the foundation in a traditional mentoring relationship.

Traditional mentoring also relies on organizational support [12], since the information exchange is typically carried out on company time, with company resources and is an intra-organizational relationship. Traditional mentoring is virtually impossible to sustain without organizational support since it can require significant human resources and be costly to administer [12].

Traditional mentoring can also be problematic for individuals belonging to minority and/or vulnerable groups. Because traditional mentoring relies on mentors and mentees exchanging information in the same physical space, each person involved in the exchange picks up on physical attributes either consciously or subconsciously. Just as stereotypes can surface and be applied both with and without conscious awareness, racism and other forms of discrimination can too [12,15]. Both the mentee and mentor can skew their judgments within the communication exchange based on prejudices or discrimination, whether it is intentional or not. These biases can impede the egalitarian quality of the exchange between the mentor and mentee [16].

Similarly, social cues are also exchanged in a traditional mentoring relationship and the risk for both the mentor and mentee to be stigmatized by the other is present; "Individuals who, by virtue of their membership in a particular social group, or by possession of a particular characteristic, are targets of negative stereo-types, are vulnerable to being labeled as deviant, and are devalued in society" [17].

\subsection{Negative Aspects of Mentoring}

As with any professional program, mentoring also has potential negative affects. Mentoring programs and relationships are goal orientated. Goals are established between the mentor and mentee at the outset of the relationship, as well as redefined throughout the relationship. As goals are achieved, new goals are set. Many mentees seek a mentoring relationship to assist them in advancing their careers and set their goals based on this hope. For this reason, mentees who participate in a relationship where there are few opportunities for advancement within an organization can often become frustrated [12] as their goal to further their career may not be realistic. 
An organization that allows a mentoring program to proceed where there is insufficient organizational commitment risks the mentoring program to be negatively perceived by others [12]. Inter-organizational perceptions of a mentoring program and/or its participants will either add to the success of the program or detract participants and the organization from achieving their mentoring goals. Resentment may also arise from participants who have unrealistic promotional expectations and with nonparticipants who may perceive the program is based on favoritism [12].

Mentoring can also involve an opportunity cost if the mentoring relationship is not advantageous to one or both parties. Specifically, if the mentoring relationship is negative for one or both parties, then it is an investment that uses resources (e.g., time, effort) that are then unavailable for others to use [10]. Similarly, poor mentoring relationships may generate poor career-related outcomes [10] for either or both the mentor and mentee.

In addition, mentoring relationships can cause burden for the mentor if the mentee is overly dependant on the mentor [12]. Similarly, the mentee may feel anxious and overloaded if the mentor's expectations of them are unrealistic. Likewise, mentoring can become too time-consuming for all parties involved, just as poorly matched mentors and mentees can create frustrations and/or work tensions. The over use of mentors can create not only mentor fatigue, but a weak or poor performing mentor that is over used has the potential to duplicate their traits in their mentees, further replicating their poor work style within the organization or profession [12]. A brief summary of the drawbacks of mentoring programs is provided in Table 2.

\section{E-Mentoring}

In order to address the limitations and negative aspects of traditional mentoring, organizations have turned to ementoring. E-mentoring is "a computer-mediated relationship between a senior individual who is the mentor, for a lesser skilled mentee with the goal of developing

Table 2. Drawbacks of mentoring programs.

\begin{tabular}{|c|c|c|}
\hline Organization & Mentee & Mentor \\
\hline $\begin{array}{l}\text { - Lack of } \\
\text { organizational support } \\
\text { - Creation of a climate } \\
\text { of dependency } \\
\text { - Difficulties in } \\
\text { coordinating programs } \\
\text { with organizational } \\
\text { initiatives } \\
\text { - Costs and resources } \\
\text { associated with } \\
\text { overseeing and } \\
\text { administering programs }\end{array}$ & $\begin{array}{l}\text { - Neglect of core job } \\
\text { - Negative experiences } \\
\text { - Unrealistic experiences } \\
\text { - Overdependence on the } \\
\text { mentoring relationship } \\
\text { - Role conflict between } \\
\text { boss and mentor }\end{array}$ & $\begin{array}{l}\text { - Lack of time } \\
\text { - Lack of perceived } \\
\text { benefits } \\
\text { - Lack of skills } \\
\text { needed for the } \\
\text { mentoring role } \\
\text { - Pressure to take on } \\
\text { mentoring role } \\
\text { - Resentment of } \\
\text { mentees }\end{array}$ \\
\hline
\end{tabular}

the mentee in a way that helps him or her succeed" [16]. It is further defined as "a computer mediated, mutually beneficial relationship between a mentor and a mentee which provides learning, advising, encouraging, promoting, and modeling, that is often boundary less, egalitarian, and qualitatively different than traditional face-to-face mentoring” [16]. E-mentoring is augmented by technology and comes in many different forms. While technology is the enabling instrument in an e-mentoring relationship, it still is powered by and focused on humans [18]. Table 3, although not exhaustive, represents the most frequently used mediums used in e-mentoring.

\subsection{Traditional vs. E-Mentoring}

E-mentoring is distinguished from traditional mentoring by it's geographically boundary less configuration and its egalitarian quality of the exchange [16]. E-mentoring is also unique as it "challenges the conventional wisdom that mentoring must be based on personal, face-to-facerelationships” [16]. Traditional mentoring required that mentees and mentors meet at regular intervals to carry out their exchange of information. Many organizations have down sized and faced significant cut backs, which can no longer afford the monetary, human or resource cost of traditional mentoring programs. Training envelopes have suffered as a result and depleted resources required to sustain formal mentoring programs and their administration [18]. As such, companies have incurporated e-mentoring programs in their training portfolios as the e-mentoring programs pay for themselves [18] while adding considerable benefits to mentor, mentee and the organization itself.

Table 3. E-mentoring tools [18].

\begin{tabular}{|c|c|}
\hline E-mail & The most basic e-mentoring medium \\
\hline Online discussion groups & $\begin{array}{l}\text { Allows a mentor to reach more than } \\
\text { one mentee at once }\end{array}$ \\
\hline Instant messaging and chat & $\begin{array}{l}\text { Provides the immediacy of direct } \\
\text { conversation without the need to } \\
\text { meet in person }\end{array}$ \\
\hline Video conferencing & $\begin{array}{l}\text { Puts faces to names and personalizes } \\
\text { the e-mentoring relationship without } \\
\text { the difficulty of travelling to meet } \\
\text { each other }\end{array}$ \\
\hline Blogs & $\begin{array}{l}\text { Allows mentors and mentees to } \\
\text { record their thoughts and share them } \\
\text { with others as they occur, and allows } \\
\text { others to comment }\end{array}$ \\
\hline Wikis & $\begin{array}{l}\text { Allows mentors and mentees to } \\
\text { create a collaborative Web site with } \\
\text { information about both mentoring } \\
\text { and their profession }\end{array}$ \\
\hline Document sharing & $\begin{array}{l}\text { Allows mentees to solicit input from } \\
\text { mentors on documents they've } \\
\text { created; allows mentors to share } \\
\text { educational materials }\end{array}$ \\
\hline
\end{tabular}


Online transactions are gaining popularity because of the ease of engaging from almost anywhere, at any time. Likewise, e-mentoring is also gaining popularity as the internet becomes more commonplace in professional and training transactions. Just as the retail industry has seen a dramatic increase in the use of online retail spending [19], e-mentoring has also significantly increased and replaced many formal and traditional mentoring programs/relationships in organizations. An overview of the benefits of traditional mentoring versus e-mentoring can be found in Table 4.

\subsection{Benefits of E-Mentoring}

E-mentoring has low barriers to entry and access. E-mentoring simply requires internet access, an email account and a small commitment of time [16]. E-mentoring is limitless in that it crosses many boundaries that are rarely crossed in traditional mentoring-race, gender, geography, age and hierarchy [16]. Moreover, e-mentoring provides access to mentoring for those on sabbatical from their traditional professional roles, such as individuals on maternity and paternity leave, individuals on education leave and those temporarily out of the workplace to care for elderly parents.

E-mentoring is particularly beneficial to individuals of marginalized groups, as the e-component of the relationship decreases markers of social status as they are less visible in the electronic exchange [16]. The traditional power dynamics are eroded in an e-mentoring relation-

Table 4. Traditional mentoring vs. e-mentoring [18].

\begin{tabular}{|c|c|}
\hline Traditional Mentoring & E-Mentoring \\
\hline $\begin{array}{l}\text { Local; pool of mentors limited } \\
\text { to those in geographic area }\end{array}$ & $\begin{array}{l}\text { Global; pool of mentors is unlimited; } \\
\text { matched according to background, } \\
\text { interest, and area of expertise }\end{array}$ \\
\hline & $\begin{array}{l}\text { Mentors and mentees may } \\
\text { electronically participate in multiple }\end{array}$ \\
\hline One-on-one; face-to-face & $\begin{array}{l}\text { mentoring relationships } \\
\text { simultaneously; allowing participants } \\
\text { to expand their professional networks }\end{array}$ \\
\hline Scheduled meetings & $\begin{array}{l}\text { Mentoring conversations may occur } \\
\text { any time the mentee has a question or } \\
\text { the mentor has advice to share, often } \\
\text { with instant feedback, as often or as } \\
\text { rarely as necessary }\end{array}$ \\
\hline \multirow{3}{*}{ Extemporaneous conversation } & Written discourse provides time for \\
\hline & $\begin{array}{l}\text { thoughtful reflection and greater } \\
\text { candor }\end{array}$ \\
\hline & Ability to have multiple mentors \\
\hline General in scope & $\begin{array}{l}\text { allows for narrow scope of subject } \\
\text { matter discussed with each; more } \\
\text { intense, focused mentoring }\end{array}$ \\
\hline Typically long term & $\begin{array}{l}\text { May be long-term relationships, } \\
\text { project-length collaborations, or brief } \\
\text { mini-mentorships }\end{array}$ \\
\hline $\begin{array}{l}\text { Organization-wide traditional } \\
\text { mentoring programs require } \\
\text { significant staff time and money }\end{array}$ & $\begin{array}{l}\text { E-Mentoring software eases the } \\
\text { administrative burden of a large } \\
\text { mentoring program and costs less than } \\
\text { bringing mentors together in person }\end{array}$ \\
\hline
\end{tabular}

ship and as a result individuals of marginalized groups are often accelerated in gaining access to non-traditional occupations by virtue of being provided access to role models and advocates [16]. Bierema and Merriam provides that "While technology can be viewed as an impersonal approach, the medium promotes easier access and perhaps more candid communication than would occur face-to-face. The cultural baggage and stereotypes that accompany race, gender and social class becomes invisible in a virtual forum, freeing the mentoring to become the focus” [16].

Administratively, e-mentoring provides the ability to network with one or more mentors or mentees at any given time, in a cost and time efficient manner [18]. Further, e-mentoring provides the ability to exchange large amounts of information between individuals in relatively short time spans and with little effort [16]. An e-mentoring relationship can also be facilitated when it is convenient for each participant, not only at times when mutually agreeable, as is the case in a traditional face-toface mentoring relationship where both parties must be physically present at the same time and location [16]. E-mentoring allows for participants to access and respond to communications according to their own schedule, and provides a mechanism to record transactions, which allows for further reflection at a later time by either party.

Just as e-mentoring allows for greater access to individuals it also provides for a variety of different perspectives [18]. The E-Mentor Illinois program, a program designed to provide e-mentoring for new teachers with more experienced teachers throughout the state of Illinois, highlighted that in traditional mentoring relationships the mentors perspective can limit the mentee as the mentors way often seems like the only way [18]. E-mentoring allows for a collaboration of individuals, greater access to larger networks, professionals and cultures [16] than would otherwise be available locally [18], and all within a simultaneous and instantaneous environment. Individuals are able to eliminate wait times of face-to-face meetings and provides for individuals to communicate on an as-needed basis, when ideas and thoughts are fresh in their mind making the exchange of information more significant [18].

Some argue that e-mentoring relationships can be harder to develop than traditional face-to-face mentoring [15]. Communications can become strained in an e-mentoring relationship, especially if the interactions are brief and/or infrequent [20]. E-mentoring also lacks the nonverbal cues (pitch, flow of speech, facial expressions, body language) and communications can easily be misinterpreted [20]. Some researchers argue that face to face relationships are essential, as the social distance in an e-environment not only impedes the relationship, but 
limits the communications. However, Lea and Spears [21] point out that there was considerable debate about social distance when the telegraph and telephones first became a mainstream mode of communication [22] and such debates are virtually non-existent now.

It is also important to acknowledge that e-mentoring integrates one or more different modes of communication from a distance such as email, telephone, videoconferencing, web cameras, texting, chats, blogs, wikis, online discussions, and instant messaging [20]. These types of internet communications are commonly referred to as computer-mediated communication (CMC) and focus on the linguistic characteristics of the interaction [22]. Because participants exchange information through CMCs, the communications become more intentional and context-rich as participants become more collaborative [18] and less concerned with external stimuli.

\subsection{Limitations of E-Mentoring}

The likelihood of miscommunication is increased in an e-mentoring relationship as both the mentee and mentor rely on asynchronous communication exchanges [15]. Ementoring can also result in a slower progression of relationship development as compared to traditional mentoring due to the many modes of communication that can be used and the unpredictability of these communications [15]. Variability in writing style and a gap or lack of technical skills between parties can also create a digital divide and weaken the quality of communications [15].

E-mentoring has a unique challenge of privacy issues, as the exchange between mentor and mentee is recorded in the communication exchange [16]. While it can be beneficial to reflect on previous communications, the potential for private and personal information to be shared, intentionally or accidentally, with others is always pre sent when it is recorded electronically. For this reason, there may be reluctance for either party within the relationship to provide certain information when exchanging CMCs.

However, the main challenges of e-mentoring is in the matching process, the development of the relationship, as well as establishing trust and confidence after the relationship is initiated [16]. As many e-mentoring relationships are formed without a formal program and/or without the help of an administrator, one or both parties may lack the training required to facilitate a meaningful relationship and/or the too1s required to sustain an e-mentoring relationship [16].

Trust is essential in a mentoring relationship as the mentee must take risks within the relationship to achieve the mentoring goals and previous research has suggested that mentoring is effective only when trust is formed between mentors and mentees [23]. However, what establishes mutual trust, respect and commitment with in- dividuals who have never met face-to-face? How do individuals decide on who to trust and how? And are there elements or phases of building trust? It is clear that more research is needed to explore how trust is formed in e-mentoring. Therefore, the purpose of this paper is to present a research agenda to advance our understanding of forming trust in e-mentoring. We draw our hypotheses from two bodies of literature: forming interpersonal trust and forming online trust.

\section{Interpersonal Trust}

Trust is defined as "a psychological state comprising the intention to accept vulnerability based on positive expectations of the intentions or behaviours of another" [24]. Trust involves one individual to accept vulnerability with an expectation of relying on another individual [25].

Mayer, Davis \& Schoorman [26] provide a widely accepted framework that describes how trust is formed between individuals. Mayer's model involves two individuals: a trusting party called the trustor, and a party to be trusted called the trustee [26]. Mayer et al. define trust as "the willingness of a party to be vulnerable to the actions of another party based on the expectation that the other will perform a particular action important to the trustor, irrespective of the ability to monitor or control the other party" [26]. In Figure 1, Mayer et al. provide that trust is affected by the trustor's propensity to perceive the trustee's ability, benevolence and integrity [26]. These three factors provide a unique contribution for the trustor to develop trust toward the trustee.

Ability is defined as "the group of skills, competencies, and characteristics that enable a party to have influence within a specific domain" [26]. The reference to domain is significant because the trustee could be a professional, subject matter expert or has extensive technical competence in a given domain, which leads others to automatically trust him or her [26]. However, the trustee mightlack in other areas, such as interpersonal communication,

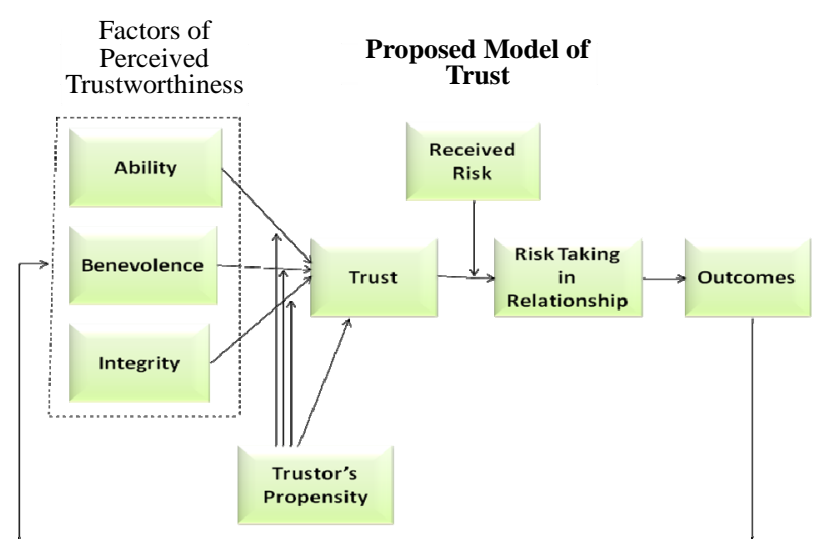

Figure 1. Proposed model of trust. 
therefore trust is domain specific for each ability assessed [26].

Benevolence is defined as "the extent to which a trustee is believed to want to do good to the trustor, aside from an egocentric profit motive" [26]. Benevolence demonstrates that the trustee has particular connections to the trustor and the mentor (trustee) would like to help the mentee (trustor) despite there is no specific reward for such behaviour [26]. Benevolence is an indication of the trustee's impression of a positive attitude toward the trustor [26].

Integrity is defined as the "trustor's perception that the trustee adheres to a set of principles that the trustor finds acceptable" [26]. The trustor will consider their credibility, their sense of justice, the consistency of their past actions and the extent to which their actions match their spoken word [26].

Mayer et al.'s model has been applied extensively in both e-mentoring and traditional mentoring in several contexts such as marketing, accounting, finance, economics, information systems, industrial engineering, political science, communication, ethics, law, psychology, sociology, health care and agribusiness $[13,27,28]$. As such, we hypothesize that it can be applied to explaining how trust is formed between mentor and mentee in ementoring. Specifically, we propose:

H1a: Mentors will trust their mentees more in an ementoring environment when they perceive that their mentee's ability to be stronger.

H1b: Mentees will trust their mentors more in an ementoring environment when they perceive that their mentor's ability to be stronger.

H2a: Mentors will trust their mentees more in an ementoring environment when they perceive that their mentee's benevolence to be stronger.

H2b: Mentees will trust their mentors more in an ementoring environment when they perceive that their mentor's benevolence to be stronger.

H3a: Mentors will trust their mentees more in an ementoring environment when they perceive that their mentee's integrity to be stronger.

H3b: Mentees will trust their mentors more in an ementoring environment when they perceive that their mentor's integrity to be stronger.

\section{Online Trust}

Rousseau et al. [24] defined online trust as "a psychological state comprising the intention to accept vulnerability based on positive expectations of the intentions or behaviors of another" [19]. Online trust is also defined by Gefen as the "expectation that commitments undertaken by another person or organization will be fulfilled" [29]. Trust is therefore essential for the individual vulnerable (usually the buyer) to the actions of another (usually the seller) [29]. Bart et al. [25] expanded on Rousseau's definition and provided that online consumer trust includes perceptions of how a consumer perceives a site would deliver on expectations, how credible a site is in the information it presents, and how much confidence can be instilled in a site [19]. While there is significant research on consumer/seller transactions, relatively little research exists on online trust outside of that experience. Most of the literature review is based on human-computer interaction and focuses on individuals trusting web sites, as opposed to individuals trusting individuals [30]. Following is a review of research on online trust that suggests avenues of future research on how trust is formed in e-mentoring.

Security and privacy are enablers of trust, and web users provide that lack of trust is the greatest barrier for consumers to engage in online transactions [19]. Trust is multidirectional and an ongoing process [19]. Just as in any online transaction, trust is rarely built in one session alone [19]. Urban et al. [19] suggest that there is a feedback loop of trust-action-learning-trust that is repeated many times until trustworthiness is established. Furthermore, trust is only established when an individual believes that his/her original expectations were met, which requires several interactions over a period of time [19]. Some research suggests that individuals with previous online experience also have a greater ability to trust in online transactions [19]. Many parallels exist between online consumer transactions and e-mentoring communications. Just as merchants engage in trust building transactions to gain consumers trust such as engaging with customers online (live chats with merchant agents) and posting customer testimonials, mentors and mentees engage in trust building transactions such as forming of positive impressions, accepting vulnerability, testing predictability, learning from previous transactions/experience, and sharing of personal information [19], both consciously and subconsciously with every information exchange. Therefore, we hypothesize:

$\mathrm{H} 4$ : Mentors and mentees will trust more the greater the frequency of their communication exchanges.

The literature also suggests a correlation between a physically attractive source (people, websites, etc.) and a perception of credibility [19]. For many online consumers, an esthetically pleasing website lends to a positive evaluation of trust and credibility [19]. In e-mentoring, physically attractive sources would include online content such as photographs, the presentation of the personal and professional experience (e.g., curriculum vita, blogs, facebook pages, etc.) and the extent to which this information is professionally presented (e.g., grammatically correct sentences). Therefore, we hypothesize:

H5a: Mentors will trust their mentees more if the mentee's online content is perceived to be more physi- 
cally attractive/professional in appearance.

H5b: Mentees will trust their mentors more if the mentor's online content is perceived to be more physically attractive/professional in appearance.

Olson and Olson (2004) studied interpersonal trust in CMC and found that information exchanges that used face-to-face, video and audio resulted in significantly higher levels of trust as compared to CMCs that relied on text chat alone [30]. Further, video and audio conference groups demonstrated higher levels of trust as they involve face-to-face communications although establishing trust was somewhat delayed and the trust formed in these relationships were more fragile in nature [30]. The same study suggested that "online interpersonal trust is closely related to the degree of liking. People who are more liked by others also gain more trust from them" [30]. One theory behind this is that as individuals provide more information about themselves, they become more likeable in the process [30]. This leads to the following hypotheses:

H6: Mentors and mentors will trust each other more as the greater their information exchanges rely on face-toface, video and audio.

H7a: Mentors will trust their mentees more when mentees provide more information about themselves.

H7b: Mentees will trust their mentors more when mentors provide more information about themselves.

Online trust between a consumer and seller is influenced by the positive and negative feedback provided by other consumers and sellers [19]. For instance, a buyer is more likely to trust a seller when previous buyers have left positive feedback (e.g., delivers product in a timely fashion) about the seller. Virtual communities rely on individuals sharing information and the sharing of information relies on both parties contributing and receiving information [31]. This leads us to the following hypotheses:

H8a: Mentors will trust their mentees more the greater the availability of positive information about the mentee.

H8b: Mentees will trust their mentors more the greater the availability of positive information about the mentor.

Finally, previous studies of online eBay transactions provide that in general, men trust more than women do, while empirical evidence shows that women are trusted more than men [32]. Several studies have demonstrated that men are more likely to engage in vulnerable transactions which display higher degrees of trust as compared to women [32]. While these studies focus on economic vulnerability (online transactions involving payment from one party to another), men were found to be more trusting than women, and men were more apt to trust without any foundation to do so [32]. This leads us to the following hypotheses:

H9: Male mentors and mentees will be more trusting than female mentors and mentees in an e-mentoring en- vironment.

H10: Female mentors and mentees are trusted more than male mentors and mentees in an e-mentoring environment.

\section{Conclusions}

E-mentoring promises to be a very effective and efficient mechanism to assist workers advance in their careers. For e-mentoring to work, however, it is essential that trust between mentor and mentee is formed, and formed as quickly as possible. The purpose of this paper was to propose a research agenda, based on the literatures examining interpersonal trust and online trust, to advance our understanding on how trust is established in e-mentoring.

The first three hypotheses based on the literature on interpersonal trust formation propose that perceptions of ability, benevolence and integrity predict trust in e-mentoring. The remaining hypotheses are drawn from the literature on online trust and propose that trust is a function of the frequency of communication exchanges, the attractiveness of the online content, the e-mentoring tools employed, the amount of personal information provided, the feedback of others and gender. Once these relationships are established, future research could explore other questions. For instance, what triggers the perception of an individual's ability, integrity and benevolence in a virtual environment? How should e-mentoring websites be designed to maximize perceptions of attractiveness and facilitate sharing of personal information and feedback? Future research should also consider longitudinal designs to explore how trust is initially formed and how it grows in the course of the e-mentoring relationship.

\section{Acknowledgements}

The authors would like to thank the Social Sciences and Humanities Research Council of Canada for financial support for this research.

\section{REFERENCES}

[1] R. Day and T. Allen, "The Relationship between Career Motivation and Self-Efficacy with Protégé Career Success,” Journal of Vocational Behavior, Vol. 64, No. 1, 2004, pp. 72-91.

[2] G. Dreher and J. Chargois, "Gender, Mentoring Experiences, and Salary Attainment among Graduates of a Historically Black University,” Journal of Vocational Behavior, Vol. 53, No. 3, 1998, pp. 401-416. doi:10.1006/jvbe.1997.1622

[3] G. Dreher and T. Cox, "Race, Gender and Opportunity: A Study of Compensation Attainment and the Establishment of Mentoring Relationships," Journal of Applied Psychology, Vol. 81, No. 3, 1996, pp. 297-308. 
doi:10.1037/0021-9010.81.3.297

[4] E. Fagenson, “The Mentor Advantage: Perceived Career/ Job Experiences of Protégés versus Non-Protégés,” Journal of Organizational Behavior, Vol. 10, No. 1, 1989, pp. 309-320. doi:10.1002/job.4030100403

[5] M. Forret and S. de Janasz, "Perceptions of an Organization's Culture for Work and Family: Do Mentors Make a Difference? Career Development International, Vol. 10, No. 6-7, 2005, pp. 478-492. http://dx.doi.org/10.1108/13620430510620566

[6] C. Kirchmeyer, "Demographic Similarity to the Work Group: A Longitudinal Study of Managers at the Early Career Stage,” Journal of Organizational Behavior, Vol. 16, No. 1, 1995, pp. 67-83.

[7] K. Kram, "Phases of the Mentor Relationship," Academy of Management Journal, Vol. 26, No. 4, 1983, pp. 608625. doi:10.2307/255910

[8] T. Scandura and E. Williams, "An Investigation of the Moderating Effects of Gender on the Relationship between Mentoring Initiation and Protégé Perceptions of Mentoring Functions,” Journal of Vocational Behavior, Vol. 59, No. 1, 2001, pp. 342-363. doi:10.1006/jvbe.2001.1809

[9] H. Van Emmerik, S. Baugh and M. Euwema, "Who Wants to Be a Mentor? An Examination of Attitudinal, Instrumental, and Social Motivational Components," Career Development International, Vol. 10, No. 4, 2005, pp. 310-324. doi:10.1108/13620430510609145

[10] S. Hezlett and S. Gibson, "Linking Mentoring and Social Capital: Implications for Career and Organization Development," Advances in Developing Human Resource, Vol. 9, No. 3, 2007, pp. 384-412. doi:10.1177/1523422307304102

[11] R. Hopkins and E. Grigoriu, "Mentoring Community College Faculty and Staff: Balancing Contradictions of Informal Program Components and Formal Program Structure," Community College Review, Vol. 32, No. 4, 2005, pp. 40-56. doi:10.1177/009155210503200404

[12] L. Ehrich and B. Hansford, "Mentoring: Pros and Cons for HRM," Asia Pacific Journal of Human Resources, Vol. 37, No. 3, 1999, pp. 92-107. doi:10.1177/103841119903700307

[13] T. D. Allen, M. L. Poteet, L. T. Eby, L. L. Lentz and L. Lima, "Career Benefits Associated with Mentoring for Protégés: A Meta-Analysis,” Journal of Applied Psychology, Vol. 89, No. 1, 2004, pp. 127-136. doi:10.1037/0021-9010.89.1.127

[14] M. Hale, "Mentoring Women in Organizations: Practice in Search of Theory," American Review of Public Administrations, Vol. 25, No. 4, 1995, pp. 327-339.

[15] E. A. Ensher and S. E. Murphy, "E-Mentoring: Next-Generation Research Strategies and Suggestions,” In: B. R. Ragins and K. E. Kram, Eds., The Handbook of Mentoring at Work: Theory, Research, and Practice, Sage, Thousand Oaks, 2007, pp. 299-322.

[16] L. Bierema and S. Merriam, "E-Mentoring: Using Computer Mediated Communication to Enhance the Mentoring Process," Innovative Higher Education, Vol. 26, No. 3, 2002, pp. 211-227.
doi:10.1023/A:1017921023103

[17] B. Major and J. Crocker, "Social Stigma: The Affective Consequences of Attributional Ambiguity," In: D. M. Mackie and D. L. Hamilton, Eds., Affect, Cognition, and Stereotyping: Interactive Process in Intergroup Perception, Academic, New York, 1993, pp. 345-370.

[18] S. An and R. Lipscomb, "Instant Mentoring: Sharing Wisdom and Getting Advice Online with E-Mentoring,” Journal of the American Dietetic Association, Vol. 110, No. 8, 2010, pp. 1148-1155. doi:10.1016/j.jada.2010.06.019

[19] G. Urban, C. Amyx and A. Lorenzon, "Online Trust: State of the Art, New Frontiers, and Research Potential,” Journal of Interactive Marketing, Vol. 23, No. 2, 2009, pp. 179-190. doi:10.1016/j.intmar.2009.03.001

[20] K. Purcell, "Making E-Mentoring More Effective,” American Journal of Health-System Pharmacy, Vol. 61, 2004, pp. 284-286.

[21] M. Lea and R. Spears, "Love at First Byte? Building Personal Relationships over Computer Networks,” In: J. T. Wood and S. W. Duck, Eds., Understudied Relationship: Off the Beaten Track, Sage, Newbury Park, 1995, pp. 197-233.

[22] M. Whitty and J. Gavin, “Age/Sex/Location: Uncovering the Social Cues in the Development of Online Relationships," Cyber Psychology \& Behavior, Vol. 4, No. 5, 2001, pp. 623-630. doi:10.1089/109493101753235223

[23] J. D. Leck and B. Orser, "Fostering Trust in Mentoring Relationships: An Exploratory Study,” Equality, Diversity and Inclusion: An International Journal.

[24] D. Rousseau, S. Sitkin, R. Burt and C. Camerer, "Not So Different after All: A Cross-Discipline View of Trust. Academy of Management Review,” Vol. 23, No. 3, 1998, pp. 393-404.

[25] Y. Bart, V. Shankar, F. Sultan and G. Urban, "Are the Drivers and Roles of Online Trust the Same for All Web Sites and Consumers? A Large-Scale Exploratory Empirical Study,” Journal of Marketing, Vol. 69, No. 4, 2005, pp. 133-152. doi:10.1509/jmkg.2005.69.4.133

[26] R. Mayer, J. Davis and F. Schoorman, “An Integrative Model of Organizational Trust," Academy of Management Review, Vol. 20, No. 3, 1995, pp. 709-734.

[27] J. D. Leck and A. Robitaille, "Psychometric Properties of the Behavioral Trust Inventory for Measuring Trust in Mentoring Relationships,” The Journal of American Academy of Business, Vol. 17, No. 1, 2011, pp. 199-124.

[28] F. Schoorman, R. Mayer and J. Davis, “An Integrative Model of Organizational Trust: Past, Present, and Future," Academy of Management Review, Vol. 32, No. 2, 2007, pp. 344-354. doi:10.5465/AMR.2007.24348410

[29] D. Gefen, "Reflections on the Dimensions of Trust and Trustworthiness among Online Consumers,” ACM Sigmis Database, Vol. 33, No. 3, 2002, pp. 38-53.

[30] J. Feng, J. Lazar and J. Preece, "Empathy and Online Interpersonal Trust: A Fragile Relationship,” Behaviour \& Information Technology, Vol. 23, No. 2, 2004, pp. 97-106. doi:10.1080/01449290310001659240

[31] W. Shu and Y. Chuang, "Why People Share Knowledge in Virtual Communities," Social Behaviour and Person- 
ality, Vol. 39, No. 5, 2011, pp. 671-690.

[32] R. Reidl, M. Hubert and P. Kenning, “Are There Neural Gender Difference in Online Trust? An FMRI Study on the Perceived Trustworthiness of EBay Offers," MIS Quarterly, Vol. 34, No. 2, 2010, pp. 397-428. 